bone exposed. The depressed surface was less evident to the eye than to the finger, and, indeed, the whole extent of damaged external plate was comparatively trifling-a sixpenny piece would have covered it; but on raising the circular disc, loose fragments of the inner table were found in every direction round the wound. In all, twenty-three pieces were removed; some with extreme difficulty, for more than one piece was found too large for extraction through the trephine-hole, and had to be cut with bone forceps; and several sharp spiculæ had penetrated the dura mater and were sticking firmly in it. The scalp was sutured and the wound lightly dressed with dry lint. The patient, who bore the operation and somewhat prolonged administration of chloroform extremely well, was then carried home (about two miles) on an improvised stretcher, and put to bed in a dark room. His progress to recovery was uninterrupted, the treatment being low diet and quietude. In eleven days the scalp wound had almost entirely healed, with scarcely a trace of suppuration, and in fourteen days from the receipt of the injury the patient was up and convalescent; since then he has been an intelligent member of an ambulance class I organised in his village. He wears a vulcanite plate as a protection over the scar; but the dense and strong cicatricial tissue which is rapidly forming will probably of itself soon afford all protection necessary for what the patient fecetiously calls the "only soft spot in his head."

The interesting features in the case are (1) the very slight damage sustained by the external table of the skull when compared with the condition of the inner; the separated pieces of the latter weighed $130 \mathrm{gr}$, and covered a superficial area greater than that of a five-shilling piece; (2) the entire absence of symptoms of intra-cranial mischief, excep the immediate insensibility due to concussion. The temperature never rose above $99^{\circ}$, though the dura mater was lacerated in several spots. The circumstances of the operation were somewhat unusual, the patient lying on a low and narrow settle fixed to the wall in a badly lighted farmhouse kitchen, and the only available nurse a gamekeeper. The case bears an interesting similarity in some particulars to one that came under my observation when house-surgeon at our local infirmary, and which I reported in THe LANCET at that time. In that case, which ended fatally, the blow was concentrated on one spot, having been administered by a lusty Irish woman with the knobby end of a kitchen poker. There being no urgent brain symptoms, and not very distinct evidence of depression and comminution of bone, the expectant treatment was adopted, but the necropsy revealed abundant evidence of meningitis, cerebral abscess, and a depressed comminuted fracture with very sharp edges. Southport.

\section{ANTISEPTIC MIDWIFERY.}

\section{By Ambrose E. L. Charpentier, M.B.}

IT is with much pleasure I see the increasing interest taken in the above subject, and notably Dr. W. A. Duncan's most instructive paper on the "Accidents of Parturition." As one practising antiseptic midwifery, I beg to offer one or two suggestions, chiefly as to the means of carrying it out in ordinary practice.

Though not presuming to write "as one having authority," I would submit that there should be some additions in the "antiseptic" midwifery bag. It should contain as usual: forceps, catheter with tubing, syringe with uterine tube, pocket case, elastic or linen bandages for "auto-infusion" in case of collapse from hæmorrhage, hypodermic syringe stylet, minim measure, and, advantageously for the safety of the patient and one's own comfort, a small nail-brush in metal case. There should be spaces for at least nine bottles; the six would contain, as in ordinary use, chloroform or the A C.E. mixture, ergot, ammonia, ether, opium, and iron. In the others there should be-(1) A solution of chloral hydrate, twenty grains of chloral in a drachm of syrup of ginger or orange. (2) Bichloride tampons, carbolic acid, or a solution of bichloride of mercury, made by dissolving 160 grains of the salt in four ounces of spirits of wine; one drachm of the solution in a pint of water forms the 1 in 2000 lotion. I find this solution superior to the tampons; it is always easily prepared, is less bulky and less expensive. (3) Ân ointment of bichloride and vaseline (1 in 500), which is conveniently carried in a wide-mouthed bottle.
As regards the actual work, there is but little more trouble and a great deal more satisfaction than in the old happy-go-lucky method. In the syringing, a china toothbrush tray, or soap-dish (almost always to be found), answers well to catch the escaping fluid when held close to the nates, the patient lying on her side in the usual position. This is easily done without any elaborate or expensive apparatus.

The universal practice of antiseptic mid wifery cannot be too strongly insisted upon, and no trouble or anxiety on our part should be too great to prerent the horror of a case of septicæmia; and when we see by the mortality tables of puerperal women, as given in Kucher's excellent book on the Puerperal Diseases, that 10 to 18 per cent. of lying-in womer die of puerperal diseases, and of these septicæmia claims 75 per cent., it is truly lamentable, and it should require no further incentive to urge us to make every effort to reduce such a terrible death-rate.

Uxbridge.

\section{LODGMENT OF A TOOTH-PLATE IN THE GULLET} FOR FIFTEEN MONTHS.

By Henry E. Bridgman, L.R.C.P.L.

Aт 2 A.M. on April 17th, 1886, Thomas H-, aged twentyeight, was brought to my surgery. He informed me that he had gone to bed, as was his habit, wearing a small plate, to which were attached four false teeth. He awoke, feeling the plate slipping into his throat, and he could, he said, still feel it at the top of his gullet. The patient was nervous and excited; he frequently retched, and expectorated bloodstained saliva; dyspnoea and dysphagia were marked. I examined the pharynx carefully with the finger, but failed to feel any foreign body. With a pair of throat forceps I seized something that I believed to be the plate, but on making an attempt to withdraw it, the dyspnoea increased, the patient struggled, and the forceps slipped. After several

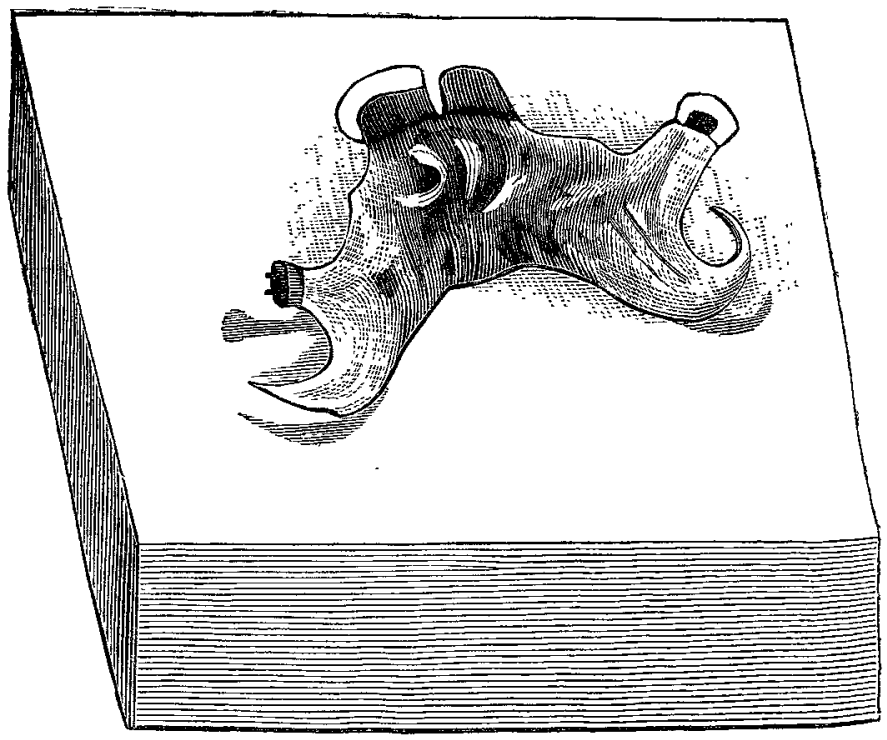

fruitless attempts to seize the plate a second time, I desisted, and sent my patient to the Burton-on-Trent Infirmary. There probangs were passed into the stomach without meeting with any obstruction. The patient was watched for a few days, and then discharged, the dyspnoea and dysphagia having disappeared.

I saw the man a few weeks afterwards, when he was again suffering from dyspnœea, had a hard, frequent cougb and was expectorating copiously a tenacious mucus, tinged with blood. I continued to see him from time to time until Christmas, 1886. On July 25th, $18 \pm 7$, he presented himself again at my surgery, bringing with him the plate with false teeth attached, of which I enclose a sketch, saying that he had continued much in the same condition as when I had last seen him, being frequently unable to go to his work on account of cough and difficulty of breathing, until July 21st, when, being rather worse than usual, he felt, after a violent fit of retching, something in the back of his throat, when, by means of his thumb-nail, he hooked out the false teeth, which he brought with him and which he had lost just fifteen months since. Burton-on-Trent. 